\title{
The impact of residential status on cognitive decline among older adults in China: Results from a longitudinal study
}

\author{
Hanzhang $X u^{1,2^{*}}$, Matthew E. Dupre ${ }^{3,4,5}$, Danan $\mathrm{Gu}^{6}$ and Bei $\mathrm{Wu}^{7}$
}

\begin{abstract}
Background: Residential status has been linked to numerous determinants of health and well-being. However, the influence of residential status on cognitive decline remains unclear. The purpose of this research was to assess the changes of cognitive function among older adults with different residential status (urban residents, rural-to-urban residents, rural residents, and urban-to-rural residents), over a 12-year period.

Methods: We used five waves of data (2002, 2005, 2008/2009, 2011/2012, and 2014) from the Chinese Longitudinal Healthy Longevity Survey with 17,333 older adults age 65 and over who were interviewed up to five times. Cognitive function was measured by the Mini Mental State Examination (MMSE). Multilevel models were used regarding the effects of residential status after adjusting for demographic characteristics, socioeconomic factors, family support, health behaviors, and health status.

Results: After controlling for covariates, significant differences in cognitive function were found across the four groups: rural-to-urban and rural residents had a higher level of cognition than urban residents at baseline. On average, cognitive function decreased over the course of the study period. Rural-to-urban and rural residents demonstrated a faster decline in cognitive function than urban residents.

Conclusions: This study suggests that residential status has an impact on the rate of changes in cognition among older adults in China. Results from this study provide directions for future research that addresses health disparities, particularly in countries that are undergoing significant socioeconomic transitions.
\end{abstract}

Keywords: China, Cognitive decline, Older adults, Residential status

\section{Background}

The aging population in China has grown dramatically over the past several decades. Between 2000 and 2013, the number of Chinese aged 65 and older increased from 90 million to more than 200 million [1]. By 2050, this segment of the population is projected to increase to more than 300 million and will account for approximately $30 \%$ of the entire population [1]. As the number of older adults increases, so has the number of elderly living with some form of cognitive impairment. For example, a recent epidemiological study showed that the prevalence of mild cognitive impairment (MCI) in China

\footnotetext{
* Correspondence: hanzhang.xu@duke.edu

${ }^{1}$ Duke University School of Nursing, Durham, NC, USA

${ }^{2}$ Duke Global Health Institute, Duke University Medical Center, Durham, NC, USA

Full list of author information is available at the end of the article
}

was $20.1 \%$ among older adults aged 60 or above [2]. In addition, it is estimated that around 6\% of the older adults with MCI progress to dementia annually [3]. Such increase in cognitive impairment in aging populations have major societal and human implications [4]. Studies show that persons with cognitive impairment are at greater risk of physical disabilities, disease comorbidities, hospital admissions, and subsequent mortality than their cognitively normal counterparts [4-7]. Therefore, recent research has increasingly sought to understand the factors contributing to cognitive decline in older adults.

In the context of an aging population, China has also undergone a rapid urbanization due to its significant economic growth and social mobility in recent decades [8]. The share number of urban population increased from $19.4 \%$ in 1980 to $54.4 \%$ in 2014 [9]. One of the key 
contributors to the growing urban population is internal (rural-to-urban) migration among adult populations [8]. In 2010, the number of internal migrants in China reached 221 million-nearly $1 / 6$ of the nation's total population-and is projected to double in the next 10 years [10]. The implications of these massive demographic changes are not without health consequences. Indeed, there is now increasing evidence to suggest significant health disparities among urban residents, rural residents, and internal migrants in China $[11,12]$. Although findings have been mixed, most studies have demonstrated a "healthy migrant effect"-the observed finding that people who migrate are often healthier than those who did not migrate $[13,14]$. Accordingly, research has shown that rural-tourban migrants in China report better self-rated health than their rural counterparts [13]. Those who migrate to urban areas also exhibit lower rates of acute illnesses and disabilities relative to native urban residents $[15,16]$. However, almost all these previous studies used crosssection data, research is lacking in our understanding of changes in health status, such as cognitive function, in relation to changes of residential status, as the results of urbanization and migration in China. Furthermore, we know surprisingly little about the potential factors associated with stability (or change) in urban-rural residence that may influence trajectories of cognitive function in later life.

This study uses multiple waves of the Chinese Longitudinal Healthy Longevity Survey (CLHLS) to examine agerelated trajectories of cognitive function among older adults living in urban and rural areas of China. We investigate whether and to what extent stability or change in residence-i.e., native urban residence, native rural residence, rural-to-urban residence, and urban-to-rural residence-is associated with changes in cognitive function over a period of a decade. We also examine a wide breadth of socioeconomic, family support, behavioral, and health-related factors that may be contributing to the associations. The public health and policy implications of the findings are discussed.

Since the economic reforms in 1979, China has experienced significant economic growth and social changes [17]. During this period, an acceleration of urbanization occurred throughout eastern regions of the nation and the number of rural-to-urban migrants increased steadily through the beginning of the twenty-first century $[18,19]$. The demographic shift occurring from widespread geographic mobility in China has been described as one of most extensive migrations in the human history [20]. Furthermore, many of those residing in China also experienced varying degrees of hardship from World War II, the Cultural Revolution, periods of hunger or starvation, limited educational opportunities, and other consequences of dynamic changes in socio-political institutions
[21]. Although the patterns and processes of migration have been well documented in the complex context of China, its association with cognitive function in later life is understudied.

\section{Migration and cognitive function}

A significant number of studies have focused on the relationship between international migration (i.e., immigration) and cognitive function [22-25]. However, the results from this literature are often inconsistent and currently inconclusive-with some studies indicating that there is no association between migration and cognitive status [24, 26, 27]. Far fewer studies have focused exclusively on migration within a country (internal migration) and the evidence is similarly contradictory. From the limited research that exists, there is some support for the healthy migrant hypothesis $[13,28]$-which argues that migrants are typically healthier than those living in the receiving location (often the attributed to the selection of healthy migrants). For example, research from India showed that adults who migrated from rural to urban areas had lower rates of dementia than adults who resided in urban areas for long periods of time [28]. However, this finding was not supported by another study that demonstrated no difference in cognitive function between migrants and nonmigrants [29]. Nevertheless, both studies were limited by cross-sectional designs and only studied participants from a small geographic area.

To date, no existing studies have examined a longitudinal association between internal migration and changes in cognitive function among older adults in China. We argue that migration is an understudied social determinant of health that operates through complex and multifactorial pathways over time. From a life course perspective, migration (or the change of residential status) is associated with a number of socioeconomic, occupation, environment, social support, behavioral, and health-related factors that can have a cumulative and lasting impact on later-life trajectories of cognitive health.

An individual's socioeconomic status (SES) might change along with the migration process. For example, previous studies showed that in developing countries, a large amount of rural residents migrated to urban settings for better education and working opportunities [10,30]. These advantages in SES such as education and income are considered to be protective factors of cognitive decline [31-34].

However, there may be some disadvantages related to migration. For example, changes in an individual's health behaviors are often observed from a migrant population. Rural-to-urban migrants were more likely to adapt to westernized life styles: high calorie intake, physical inactivity, and sedentary employment $[35,36]$. These unhealthy life styles are considered as risk factors of cognitive impairment [37-39]. In addition, these factors not only directly 
affect an individual's cognitive function but also increase the likelihood of developing chronic diseases such as hypertension and diabetes that have been shown to produce negative effects on later life cognition [40, 41].

Previous research reported that migrants often experienced various stressful life events, such as separating from their families, during and after the migration process [42]. In addition, a number of studies well documented the hostility and discrimination that migrants received. For example, rural-to-urban migrants are often denied access to many of the social welfare programs such as health insurance and unemployment benefits that are available to their urban counterparts, even if they are doing the same job [10]. The perceived discrimination and family separation may result in lack of social support, which has been found to have negative impact on an individual's cognitive function [43, 44].

The change in residential status may also result in changes in living and working environments. Literature suggested that people work in agricultural settings are more likely to expose pesticide that was related to decline of cognitive function [45]. In addition, open fire cooking, a major source of indoor pollution, is still more common among rural households especially in developing countries [46-48]. Indoor pollution has been shown to be associated with poorer cognitive function [49]. Therefore, moving from a rural to an urban setting are likely to have improved living and working environments, which may yield a positive influence on cognitive function.

Besides all the factors that might change during the change of residential status, other factors also determine an individual's cognitive function. For example, a growing body of literature has demonstrated the association between physical function and cognitive function $[50,51]$. Age is also a strong risk factor associated with cognitive decline [52]. Compared with male, female population reported a worse cognitive function especially in the oldest old age range [53, 54].

Overall, individual's SES, psychological well-being, health status, and health behaviors influence cognitive function both directly and indirectly. The migration process might change some of these factors therefore influence an individual's cognitive function.

\section{Hypotheses}

To our knowledge, this is the first study that examines how migration contributes to the cognitive function trajectories over a specific period of time among the CLHLS study participants. We expect that migration will play an important role in the differences in cognitive function trajectories among Chinese older adults. Based on prior empirical evidence and a life course perspective we posited the following hypotheses for analysis: Hypothesis 1: Native rural residents will tend to exhibit worse cognitive function and a faster rate of cognitive decline than native urban residents. Hypothesis 2: Compared to urban residents, both rural-tourban residents and urban-to-rural residents will show similar cognitive function at baseline but a faster rate of cognitive decline than native urban residents.

\section{Methods \\ Data}

We used multiple waves of data from the Chinese Longitudinal Healthy Longevity Survey (CLHLS) for this study. The CLHLS was designed to collect information on factors related to health and longevity in older adults from 22 provinces in mainland China [55]. The survey was administered every two to three years between 1998 and 2014. Beginning in 2000, newly recruited samples were added to replenish and augment the sample of oldest-old adults; and a smaller comparative sample of adults aged 65-80 years was added starting in 2002. The details of the CLHLS sampling design, response rates, attrition, and data quality have been described extensively elsewhere [55].

The current study draws from data collected in 2002, 2005, 2008-2009, 2011-2012, and 2014. Participants who were 90 years or older at baseline $(n=17,304)$ were excluded to reduce possible selection bias and an additional 12 participants were excluded because of missing data on cognitive function. Therefore, the total analytic sample consisted of 17,333 participants aged 65-90 at baseline who contributed 39,900 observations over the study period. Figure 1 illustrates the structure of the analytic sample by survey year, initial interview year, and survival status across waves.

\section{Measures}

\section{Cognitive function}

The Chinese version of the Mini-Mental State Examination (MMSE) was used to measure cognitive function

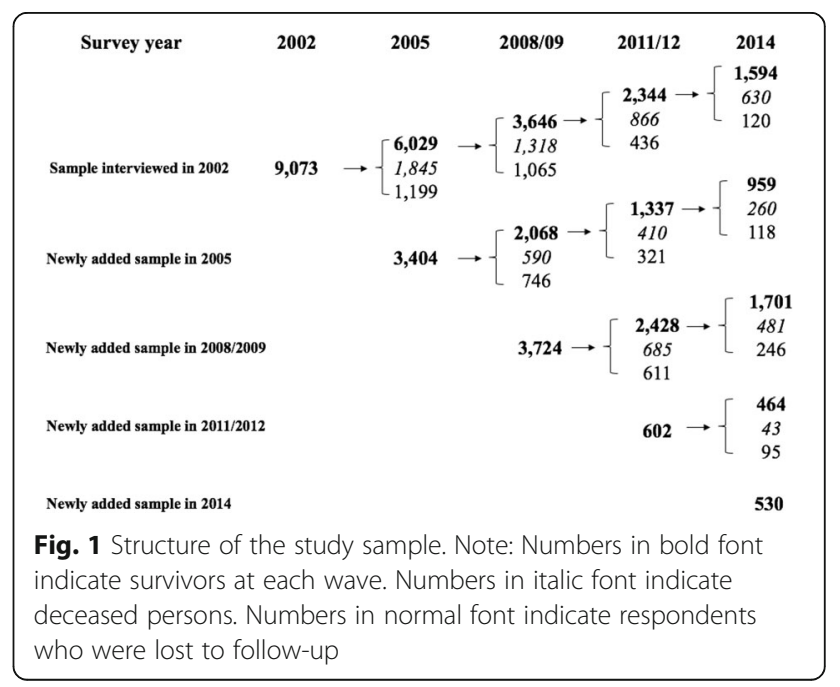


[56, 57]. The MMSE captured four dimensions of older adults' cognitive ability: cognitive orientation, calculation, recall, and language. As previously documented, several items in the Chinese version of MMSE were modified to improve their meaning and cultural acceptability [58]. The reliability and validity of the MMSE in the CLHLS has been established in prior study [58]. In particular, previous research showed that participants were more likely to be unable to answer relatively difficult tasks when they exhibited poor health and/or existing cognitive limitations [57]. Therefore, following prior research, we categorized responses of "unable to answer" as incorrect answers $[33,59,60]$. This approach is widely used in previous studies and will not introduce potential bias $[33,60]$. We also explored alternative approaches to handle the cases for "unable to answer," such as adding an additional variable in the analyses to indicate whether the participant was unable to answer any question. We found that this approach yielded very similar results as the approach used in this study. A total MMSE score was calculated and ranged from 0 to 30 , with lower scores indicating poor cognitive ability.

\section{Residential status}

Residential status was ascertained by asking participants about their residential location in early life and in adult life at each wave. Categorical variables were used to indicate participants who were: 1) rural, 2) urban, 3) rural-tourban, and 4) urban-to-rural. Persons born in rural areas and are currently living in rural areas are considered "rural;" and persons born in urban areas and are currently living in urban areas are considered "urban." Participants who were born in rural areas and currently living in urban areas were defined as "rural-to-urban" residents. Finally, participants who were born in urban areas and currently living in rural areas were defined as "urban-to-rural" residents. The categorical variables are time-varying in the prospective analyses and account for changes in adult residential location during the study period.

\section{Covariates}

Based on existing literature, we included numerous covariates that are associated with residential status and/or cognitive function (see Table 1 for details). Demographic characteristics included age (in years), gender $($ male $=1$ ), and ethnicity $(\operatorname{Han}=1)$. Socioeconomic factors included childhood SES, years of education (no education, 1-6, or $7+$ years), primary lifetime occupation (professional/administrative $=1$ ), and whether the respondent is economically independent (yes $=1$ ). Family support factors included the participants' marital status (married $=1$ ) and proximity to their children (co-residence with children or having a child living in the same village/neighborhood [high proximity] $=1$ ). Behavioral factors included smoking (current or ever smoked $=1$ ), regular consumption of vegetables (yes = 1) and fish (yes = 1), and routine exercise (yes $=1$ ). Finally, covariates for health status included having any disability in activities of daily living (ADLs) and instrumental activities of daily living (IADLs), and having any diagnosed chronic disease.

Missing data on study measures was minimal in the CLHLS sample (less than 1\%). Various strategies were assessed to address missing data (e.g., imputation, mean assignment) and the results were very similar. Therefore, the current analysis uses listwise deletion to handle missing data.

\section{Analyses}

Baseline characteristics of study participants were examined across the four residence groups. Group differences were tested using one-way ANOVA for continuous variables and chi-square tests for categorical variables. To examine changes in older adults' cognitive function across age, we used two-level multilevel models with maximum likelihood estimation-using an xtmixed procedure in Stata for analyzing longitudinal data with attrition. First, we fit unconditional models with fixed and random linear (age) and quadratic (age2) functions that were added to the intercept-only model. Tests of model fit in preliminary analyses based on BIC values (see Additional file 1: Table S1) indicated that a linear function best parameterized the pattern of cognitive decline in the data. At Level 1, we estimated a linear trajectory of individual-level changes in cognitive function as a function of increasing age. We estimated between-individual effects in the age trajectories of cognitive function at Level 2. All models also controlled for mortality and loss to follow-up. The multivariate analyses were conducted in several steps. First, demographic characteristics were included to adjust for the participants' background characteristics. Next, we included a series of models to assess how socioeconomic resources, family support, health behaviors, and health-related factors contributed to the associations. A final model was tested that included all study covariates. All of the covariates were included in the model at either level 1 (time-varying) or level 2 (time-invariant). We also estimated goodness of fit indices (i.e., deviance statistic, Akaike Information Criterion $[\mathrm{AIC}]$, and Bayesian Information Criterion [BIC]) to compare fit across the non-nested models [61].

Sampling weights were not used in the analyses because previous research indicates that the CLHLS sampling strategy was not designed as a nationally representative sample [55]. In addition, all multivariate analyses included variables used in the sampling weights (e.g., age, sex, and urban-rural residence) to produce unbiased estimates and avoid inflated standard errors [62]. Stata version 14.2 was used for all analyses. 
Table 1 Definition of Covariates

\begin{tabular}{|c|c|c|}
\hline Variable name & $\begin{array}{l}\text { Data } \\
\text { collection } \\
\text { time points }\end{array}$ & Definitions \\
\hline \multicolumn{3}{|l|}{ Demographic characteristics } \\
\hline Age & $2002-2014$ & Continuous variable \\
\hline Gender & 2002 & Male $=1$, female $=0$ \\
\hline Ethnicity & 2002 & Han $=1$, non-Han minorities $=0$ \\
\hline \multicolumn{3}{|l|}{ Socioeconomic Factors } \\
\hline Education & 2002 & No education $=0$, received $1-6$ years schooling $=1$, received 7 years or more education $=2$ \\
\hline Prof./admin. Occupation & 2002 & Professional work $=1$, others $=0$ \\
\hline Economic independence & 2002 & $\begin{array}{l}\text { A dichotomized variable with } 1 \text { if the respondent's primary financial source was from own work } \\
\text { or pension, } 0 \text { if not }\end{array}$ \\
\hline Childhood SES & 2002 & $\begin{array}{l}\text { a continuous variable ranging from } 0 \text { to } 4 \text { with } 1 \text { point each if the respondent was obtained } \\
\text { ladequate medical services, or went to bed without hunger, or if both parents were alive at } \\
\text { age } 10 \text {, or the father's occupation was white collar }\end{array}$ \\
\hline \multicolumn{3}{|l|}{ Family Support Factors } \\
\hline Marital status & $2002-2014$ & Married $=1$, others $=0$ \\
\hline $\begin{array}{l}\text { High proximity to } \\
\text { children }\end{array}$ & $2002-2014$ & $\begin{array}{l}\text { A dichotomized variable with } 1 \text { if the respondent was co-residing with children or had at least } \\
1 \text { biological children living in the same village or street block }\end{array}$ \\
\hline \multicolumn{3}{|l|}{ Behavioral Factors } \\
\hline Current smoking & $2002-2014$ & Yes $=1, \mathrm{no}=0$ \\
\hline Exercises regularly & $2002-2014$ & Yes $=1, \mathrm{no}=0$ \\
\hline Consuming vegetables & $2002-2014$ & $\begin{array}{l}\text { A dichotomized variable with } 1 \text { if the respondents said that they consumed vegetables "almost } \\
\text { every day", } 0 \text { if answered "occasionally" or "rarely or never." }\end{array}$ \\
\hline Consuming fish & $2002-2014$ & $\begin{array}{l}\text { A dichotomized variable with } 1 \text { if the respondents said that they consumed fish "almost every day", } \\
0 \text { if answered "occasionally" or "rarely or never." }\end{array}$ \\
\hline \multicolumn{3}{|l|}{ Health Status } \\
\hline Any chronic condition & $2002-2014$ & $\begin{array}{l}\text { A dichotomized variable with } 1 \text { if the respondents said that they reported hypertension, a } \\
\text { pulmonary disorder, heart attack, or cerebrovascular disease. }\end{array}$ \\
\hline Any ADL disability & $2002-2014$ & $\begin{array}{l}\text { A dichotomized variable with } 1 \text { if the respondents said that they needed any help in performing } \\
\text { the following tasks: bathing, dressing, toileting, indoor transferring, maintaining continence, and eating. }\end{array}$ \\
\hline Any IADL disability & $2002-2014$ & $\begin{array}{l}\text { A dichotomized variable with } 1 \text { if the respondents said that they needed any help in performing } \\
\text { the following tasks: visiting neighbors, washing clothes, walking one kilometer, shopping, cooking, } \\
\text { lifting } 5 \mathrm{~kg} \text {, crouching and standing up three times, and using public transportation }\end{array}$ \\
\hline Attrition & $2002-2014$ & Survivor $=0$, loss to follow-up $=1$, deceased $=2$ \\
\hline
\end{tabular}

Note: all covariates are time varying with the exception of participants' demographic and socioeconomic factors.

\section{Results}

\section{Descriptive statistics}

Baseline sample distributions are reported in Table 2 for the overall sample and by residential status. Overall, the average age of participants was approximately 78 years, the small majority were men (51\%), and most were non-Han ethnicity (94\%). More than half of the entire sample was rural residents (55.25\%) and most of the respondents (85.3\%) did not migrate during the study period. Compared with other residential groups, rural residents had significantly lower levels of education, were less likely to work in professional/administrative occupations, and were less financially independent. Rural residents were also less likely to consume vegetables and fish, less likely to engage in regular exercise, and more likely to smoke. Urban residents-and rural-to-urban residents-were younger, more likely to work in professional/administrative jobs, and were more independent financially. However, rural-to-urban residents showed the worst childhood SES among the 4 groups. Urban residents also reported the highest rates of diagnosed chronic disease and ADL disability; whereas urban-to-rural residents reported somewhat higher rates of having at least one IADL disability. Overall, the mean score of MMSE was 25.7 at baseline, with rural residents exhibited the lowest MMSE scores, followed by rural-to-urban residents, and urban residents exhibited the highest scores.

\section{Multilevel models of change in cognitive decline}

Table 3 presents the results from the multilevel models estimating the associations between residential status 
Table 2 Baseline Descriptive Characteristics of the CLHLS Study Sample

\begin{tabular}{|c|c|c|c|c|c|c|}
\hline \multirow[b]{2}{*}{ Variables } & \multirow[b]{2}{*}{$\begin{array}{l}\text { Total } \\
(n=17,333)\end{array}$} & \multicolumn{4}{|l|}{ Residence } & \multirow[b]{2}{*}{$P$ value } \\
\hline & & $\begin{array}{l}\text { Urban } \\
(n=2325)\end{array}$ & $\begin{array}{l}\text { Rural to Urban } \\
(n=5059)\end{array}$ & $\begin{array}{l}\text { Rural } \\
(n=9578)\end{array}$ & $\begin{array}{l}\text { Urban to Rural } \\
(n=371)\end{array}$ & \\
\hline \multicolumn{7}{|l|}{ Demographic characteristics } \\
\hline Age, mean (SD) & $77.9(7.87)$ & $77.3(8.10)$ & $78.3(7.80)$ & $77.5(7.94)$ & $77.8(7.84)$ & $<0.001$ \\
\hline Male,\% & 51.40 & 51.74 & 49.99 & 82.05 & 52.02 & 0.122 \\
\hline Han ethnicity,\% & 93.69 & 96.00 & 95.77 & 91.98 & 94.88 & $<0.001$ \\
\hline \multicolumn{7}{|l|}{ Socioeconomic Factors } \\
\hline \multicolumn{7}{|l|}{ Education, $\%$} \\
\hline No education & 52.28 & 31.14 & 49.38 & 59.11 & 47.98 & \multirow[t]{3}{*}{$<0.001$} \\
\hline 6 years of education & 34.41 & 35.27 & 35.93 & 33.44 & 33.15 & \\
\hline $7+$ years of education & 13.31 & 33.59 & 14.69 & 7.44 & 18.87 & \\
\hline Prof./admin. Occupation,\% & 10.62 & 25.55 & 15.81 & 4.20 & 11.86 & $<0.001$ \\
\hline Economic independence, $\%$ & 39.96 & 68.00 & 48.73 & 28.43 & 42.32 & $<0.001$ \\
\hline Childhood SES, mean (SD) & $1.73(0.77)$ & $1.80(0.85)$ & $1.72(0.78)$ & $1.73(0.74)$ & $1.86(0.76)$ & $<0.001$ \\
\hline \multicolumn{7}{|l|}{ Family Support Factors } \\
\hline Married,\% & 50.22 & 53.68 & 49.26 & 49.79 & 52.56 & 0.002 \\
\hline High proximity to children,\% & 83.29 & 70.67 & 77.98 & 89.13 & 83.83 & $<0.001$ \\
\hline \multicolumn{7}{|l|}{ Behavioral Factors } \\
\hline Current smoking, $\%$ & 24.09 & 21.29 & 21.82 & 26.02 & 22.64 & $<0.001$ \\
\hline Exercises regularly, $\%$ & 34.86 & 55.61 & 46.67 & 23.07 & 48.25 & $<0.001$ \\
\hline Consumes vegetables, $\%$ & 89.35 & 91.57 & 90.16 & 88.36 & 90.16 & $<0.001$ \\
\hline Consumes fish, $\%$ & 30.65 & 41.20 & 35.11 & 25.42 & 38.54 & $<0.001$ \\
\hline \multicolumn{7}{|l|}{ Health Status } \\
\hline Any chronic condition, $\%$ & 60.53 & 69.25 & 64.18 & 56.59 & 57.95 & $<0.001$ \\
\hline Any ADL disability, $\%$ & 12.10 & 15.14 & 15.04 & 9.95 & 8.63 & $<0.001$ \\
\hline Any IADL disability,\% & 49.91 & 46.62 & 50.56 & 50.29 & 51.75 & 0.007 \\
\hline MMSE, mean (SD) & $25.7(5.93)$ & $26.85(5.09)$ & $25.87(5.90)$ & $25.26(6.10)$ & $26.30(5.68)$ & $<0.001$ \\
\hline Died during study period, $\%$ & 41.12 & 32.56 & 44.57 & 41.12 & 47.71 & \multirow{2}{*}{$\begin{array}{l}<0.001 \\
<0.001\end{array}$} \\
\hline Loss to follow-up,\% & 28.60 & 45.42 & 35.86 & 19.25 & 33.42 & \\
\hline
\end{tabular}

Abbreviations: $S D$ standard deviation

and changes in cognitive function. Model 1 adjusted for demographic characteristics and showed that rural residents had significantly lower MMSE scores (coefficient $=-0.78 ; p<.001)$ than urban residents. In addition, rural residents and rural-to-urban migrants had significantly faster declines in cognitive function than urban residents. These patterns were largely unchanged after adding participants' family support (Model 3) and health status (Model 5) into the models.

Model 2 included socioeconomic factors and shows changes in the trajectories of cognitive function related to residential status. At baseline, rural residents exhibited significantly better cognitive function at baseline compared with urban residents when accounting for socioeconomic factors. However, the results also showed that the initially higher MMSE scores among rural and rural-to- urban migrants decline at a significantly faster rate with age compared with long-term urban residents. Model 4 included behavioral factors and further showed that there were no significant baseline differences in cognitive function related to residential status. Additional analyses indicated that engaging in routine exercise was the key behavioral factor contributing to the attenuation of MMSE differences among residence groups at baseline. Model 6 included all covariates and indicated significant differences in the initial levels and/or changes in MMSE scores for rural and rural-to-urban residence relative to urban residence. To better illustrate these findings, Fig. 2 presents the results from these analyses. In sum, we found that urban residents had the lowest MMSE scores at baseline; however, we also found that older adults who resided in rural areas, migrated from rural-to- 
Table 3 Estimates of Coefficients for Residential Status in Mixed Effect Model on Cognitive Performance, CLHLS 2002-2014

\begin{tabular}{|c|c|c|c|c|c|c|}
\hline & Model 1 & Model 2 & Model 3 & Model 4 & Model 5 & Model 6 \\
\hline$\overline{\mathrm{Age}^{\mathrm{a}}}$ & $-0.21(0.01)^{* * *}$ & $-0.18(0.02)^{* * *}$ & $-0.20(0.01)^{* * *}$ & $-0.18(0.01)^{* * *}$ & $-0.11(0.01)^{* * *}$ & $-0.07(0.01)^{* * *}$ \\
\hline \multicolumn{7}{|c|}{ Residential status (Ref: urban residents) } \\
\hline Rural-to-urban residents & $0.06(0.17)$ & $0.31(0.17)$ & $-0.05(0.17)$ & $0.26(0.17)$ & $-0.01(0.17)$ & $0.50(0.17)^{* *}$ \\
\hline Rural residents & $-0.78(0.16)^{* * *}$ & $0.38(0.17) *$ & $-0.75(0.16)^{* * *}$ & $0.08(0.16)$ & $-0.68(0.16)^{* * *}$ & $0.42(0.16)^{* *}$ \\
\hline Urban-to-rural residents & $-0.47(0.38)$ & $-0.04(0.38)$ & $-0.45(0.38)$ & $-0.09(0.38)$ & $-0.15(0.37)$ & $0.31(0.36)$ \\
\hline \multicolumn{7}{|c|}{ Age ${ }^{*}$ Residential status (Ref: Age *urban residents) } \\
\hline Age *Rural-to-urban residents & $-0.06(0.01)^{* * *}$ & $-0.06(0.01)^{* * *}$ & $-0.06(0.01)^{* * *}$ & $-0.06(0.01)^{* * *}$ & $-0.06(0.01)^{* * *}$ & $-0.07(0.01)^{* * *}$ \\
\hline Age ${ }^{*}$ Rural residents & $-0.03(0.01)^{* *}$ & $-0.04(0.01)^{* *}$ & $-0.03(0.01)^{* *}$ & $-0.06(0.01)^{* * *}$ & $-0.05(0.01)^{* * *}$ & $-0.07(0.01)^{* * *}$ \\
\hline Age *Urban-to-rural residents & $-0.01(0.03)$ & $-0.01(0.03)$ & $-0.01(0.03)$ & $-0.03(0.03)$ & $-0.05(0.02)$ & $-0.05(0.02)$ \\
\hline \multicolumn{7}{|l|}{ Demographic characteristics } \\
\hline Male & $1.25(0.06)^{* * *}$ & $0.58(0.07)^{* * *}$ & $1.12(0.06)^{* * *}$ & $1.03(0.07)^{* * *}$ & $0.91(0.06)^{* * *}$ & $0.28(0.07)^{* *}$ \\
\hline Han ethnicity & $-0.18(0.13)$ & $-0.22(0.13)$ & $-0.18(0.13)$ & $-0.28(0.13)^{*}$ & $0.07(0.12)$ & $-0.01(0.12)$ \\
\hline \multicolumn{7}{|l|}{ Socioeconomic Factors } \\
\hline \multicolumn{7}{|l|}{ Education (Ref: no education) } \\
\hline $1-6$ years of education & & $1.12(0.07)^{* * *}$ & & & & $0.94(0.07)^{* * *}$ \\
\hline $7+$ years of education & & $1.49(0.11)^{* * *}$ & & & & $1.23(0.11)^{* * *}$ \\
\hline Prof./admin. Occupation & & $0.22(0.11)^{*}$ & & & & $0.11(0.10)$ \\
\hline Economic independence & & $0.66(0.07)^{* * *}$ & & & & $0.35(0.06)^{* * *}$ \\
\hline Childhood SES & & $0.20(0.04)^{* * *}$ & & & & $0.16(0.04)^{* * *}$ \\
\hline \multicolumn{7}{|l|}{ Family Support Factors } \\
\hline Married & & & $0.50(0.07)^{* * *}$ & & & $0.25(0.06)^{* * *}$ \\
\hline High proximity to offspring & & & $-0.09(0.07)$ & & & $0.10(0.07)$ \\
\hline \multicolumn{7}{|l|}{ Behavioral Factors } \\
\hline Current smoking & & & & $0.30(0.07)^{* * *}$ & & $0.06(0.07)$ \\
\hline Exercises regularly & & & & $1.34(0.06)^{* * *}$ & & $0.82(0.06)^{* * *}$ \\
\hline Consumes vegetables & & & & $1.90(0.09)^{* * *}$ & & $1.53(0.08)^{* * *}$ \\
\hline Consumes fish & & & & $0.64(0.06)^{* * *}$ & & $0.45(0.05)^{* * *}$ \\
\hline \multicolumn{7}{|l|}{ Health Status } \\
\hline Any chronic condition & & & & & $-0.08(0.05)$ & $-0.19(0.05)^{* * *}$ \\
\hline Any ADL disability & & & & & $-3.96(0.08)^{* * *}$ & $-3.79(0.08)^{* * *}$ \\
\hline Any IADL disability & & & & & $-1.90(0.06)^{* * *}$ & $-1.62(0.06)^{* * *}$ \\
\hline \multicolumn{7}{|l|}{ Attrition (Ref: survivors) } \\
\hline Loss to follow-up & $-0.41(0.08)^{* * *}$ & $-0.47(0.08)^{* * *}$ & $-0.40(0.08)^{* * *}$ & $-0.43(0.08)^{* * *}$ & $-0.21(0.08)^{* * *}$ & $-0.26(0.08)^{* * *}$ \\
\hline Deceased & $-2.49(0.08)^{* * *}$ & $-2.45(0.08)^{* * *}$ & $-2.47(0.08)^{* * *}$ & $-2.32(0.08)^{* * *}$ & $-1.73(0.07)^{* * *}$ & $-1.62(0.07)^{* * *}$ \\
\hline \multicolumn{7}{|l|}{ Goodness of fit } \\
\hline AlC & 248,552 & 243,980 & 248,485 & 247,188 & 244,433 & 239,279 \\
\hline $\mathrm{BIC}$ & 248,681 & 244,151 & 248,631 & 247,317 & 244,588 & 239,493 \\
\hline
\end{tabular}

Abbreviations: AIC Akaike Information Criterion, BIC Bayesian information criterion

Model 1: Adjusted for demographic characteristics; Model 2: Model 1 + Socioeconomic factors; Model 3: Model 1 + Family support; Model 4: Model 1 + Behaviroal factors; Model 5: Model 1 + Health status; Model 6: full model.

${ }^{a}$ centered at age 65; Standard errors within parentheses; ${ }^{*} p$-value $<0.05 ;{ }^{* *} p$-value $<0.01 ;{ }^{* * *} p$-value $<0.001$

urban, or from urban-to-rural areas had significantly greater reductions in cognitive function with increasing age.

Several sensitivity analyses were also performed. First, the results were largely unchanged when including adults who were aged 90 and older at baseline-suggesting that selection bias at advanced ages did not play a significant role in the findings. Second, we also estimated three-level multilevel models to further include residential status as a random effect in the analyses (i.e., to account for possible 


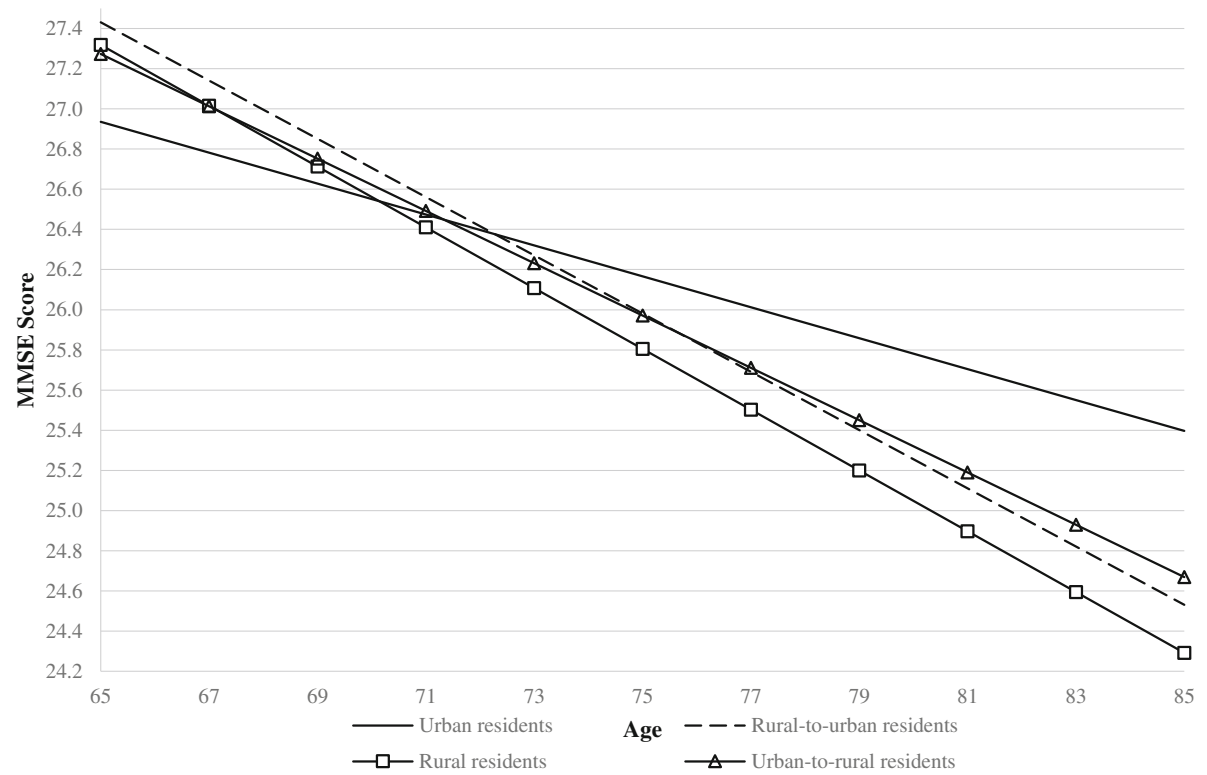

Fig. 2 Predicted Linear Trajectories of MMSE scores among Chinese Older Adults by Residential Status

nesting of respondent differences in each residential group). Third, we used baseline residential status as the predictor in the model and included a dummy variable that indicated whether the respondent moved or not during the course of the study. The results from these analyses were consistent with the findings reported here. Finally, we added a variable that indicated whether the current residential location is the same as their birthplace to account for potential urbanization in rural-to-urban resident group. The results were essentially similar to those we presented in this study.

\section{Discussion}

The purpose of this study is to examine the association between early-life and adult residential status and changes in cognitive function over time. Using longitudinal data and a time-vary indicator of residential status for older adults in China, we found significant differences in the initial levels and rates of decline in cognitive function among older adults with different residential status. Furthermore, the relationships were not fully explained by older adults' demographic background, socioeconomic resources, family support, health behaviors, and health status. The current study extends previous findings by further demonstrating how current residence and past migration can have a lasting association on trajectories of cognitive function in older adulthood [60,63].

After adjusting for all covariates, we found that rural residents had better cognitive function at baseline but a faster rate of decline than urban residents, which partially supports our first hypothesis. The observed difference in the initial level of cognitive function may be related to selective survival; whereas, the faster rate of decline may be associated with the negative consequences of living in rural areas that have been documented in previous research [64]. We also found no difference in the initial levels nor rates of decline in cognitive function between urban-to-rural residents and urban residents. This finding is somewhat in contrast to our second hypothesis. However, based on the limited evidence of urban-to-rural residents in prior studies and the relatively small size of this group, more research is needed to explore whether moving from an urban residence to a rural one could have an impact on later-life cognitive function.

The findings from this study provide only partial support to the healthy migrant hypothesis [13]. Consistent with research in India [28], we found that rural-to-urban residents had better baseline cognitive function than urban residents in China. Although this finding does not fully support our second hypothesis, the explanation for this association may be attributable in part to the selection of healthy individuals who may be more likely and/ or able to migrate [65]. Indeed, we found no difference in baseline MMSE scores between urban residents and rural-to-urban residents after taking into account the participants' health status.

Contrary to the healthy migrant effect, however, we also found that rural-to-urban residents had more rapid declines in cognitive function than their urban counterparts. This finding partially supports our second hypothesis. Although adjustments for a variety of important confounders did not explain this association, it is possible that the cumulative toll of these risk factors at earlier ages may 
have precipitated an acceleration of cognitive decline at older ages. This argument is compatible with a large body of research on the life course which demonstrates that early-life and long-term exposure to disadvantage can have consequences across the adult life span [66-69]. In the context of China, previous research has shown that living in rural areas in early life is negatively associated with cognitive function [64]. In addition, it may be that migrating from rural to urban areas may limit an individual's social network and available sources of social support from friends and family members. Studies have also suggested that rural-to-urban residents may be denied access to some of the social benefits available to their urban counterparts (e.g., retirement pension, health insurance, etc.), which may have important implications for access to health care and health maintenance [10].

An important area for future research will be to investigate the mechanisms underlying the findings from this study and to develop possible intervention strategies to reduce these risks. As expected, health status was the strongest correlate of cognitive function in our sample of older adult. Our analyses also suggested that socioeconomic and behavioral factors had among the greatest overall model fit for estimating the changes in cognitive function across age. Accordingly, we found that education, occupation, and economic independence were strongly associated with cognitive function among older adults in China. This finding is consistent with other studies showing that higher levels of SES were associated with higher overall levels of cognitive function $[60,63]$. We also found that regular exercise, and healthy diet (consuming vegetables and fish) were significantly associated with higher cognitive performance, as shown elsewhere [38, 70] .However, our results suggest that health status, socioeconomic factors, and health behaviors appear to be operating largely independent of the migration variables. Therefore, we encourage additional quantitative and qualitative studies of the possible mechanisms at play.

This study has several limitations that should be acknowledged. First, the measure of residential status in the CLHLS is relatively crude. In particular, we were unable to identify the respondent's age at migration, the reason(s) that they migrated, and multiple migrations-factors that may be important for understanding the association with cognitive health. Second, because of China's urbanization in recent decades, we recognize that some urban areas may have been rural areas in the past. Therefore, it is possible that some of the findings related to change of residential status may be attributable to urbanization. Although we did a sensitivity analysis to account for potential urbanization, we are not able to fully differentiate rural-to-urban migrants from those whose residential status changed because of urbanization. It is possible that the underlying mechanisms for these two groups may be different. For example, those whose residential status changed because of urbanization might not experience separation from family or changes in their environment. However, they may also have similar experience in terms of raising living standard, change of lifestyle, and improved access to care. We encourage future studies to consider how these and other factors may contribute to changes in cognitive function related to residential status. Third, we acknowledge that the CLHLS includes the oldest-old adults in China and thus may include some degree of bias related to selective survival. However, this issue is largely unavoidable when studying cognitive decline at later ages.

Overall, this study provided a better knowledge and understanding on the risks related to decline of cognition. Results from this study also provided guidance for future research that addresses health disparities. Future research should not only compare rural versus urban residents, but also take consideration of the migrants, a large segment of the population in developing countries, the study results are particularly useful for those countries that are undergoing a significant social transition and urbanization. In addition, this study provided insights that help us target these identified risk factors in future research, and ultimately develop effective programs and interventions to improve cognitive function.

\section{Conclusions}

In conclusion, the current study found a robust association between early-life and adult residential status and changes in cognitive function among older adults in China. These findings provide new evidence to a growing literature on the importance of social determinants in healthy aging. We encourage additional studies to corroborate the results from this study and further explore the factors that may be contributing to differential declines in cognitive health related to place of birth and adult living environments.

\section{Additional file}

Additional file 1: Table S1. Parameter Estimates for Trajectories of Cognitive function Over Time. (DOCX $35 \mathrm{~kb}$ )

\section{Abbreviations \\ ADL: Activity of daily living; CLHLS: Chinese Longitudinal Healthy Longevity Survey; IADL: Instrumental activity of daily living; MCl: Mild cognitive impairment; MMSE: Mini Mental State Examination; SD: Standard deviation; SES: Socioeconomic status}

\section{Acknowledgements}

This study was presented at the 2015 Annual Meeting of the Gerontological Society of America.

Funding

The authors declare that they have no funding support for this study. 


\section{Availability of data and materials}

The CLHLS datasets are publicly available at the National Archive of Computerized Data on Aging (ICPSR 36179) (http://www.icpsr.umich.edu/ icpsrweb/NACDA/studies/36179). Researchers may obtain the datasets after sending a data user agreement to the CLHLS team.

\section{Authors' contributions}

HX designed, drafted, and revised the text. HX also performed the analyses. DG prepared the data. MED, DG, and BW made critical revisions to the paper for significant intellectual content. All authors read and approved the final version of the manuscript.

\section{Competing interests}

DG is a section editor of the Journal, and MED is an association editor of the Journal.

\section{Consent for publication}

Not applicable.

\section{Ethics approval and consent to participate}

The CLHLS study was approved by research ethics committees of Duke University and Peking University (IRB00001052-13074). All participants provided written informed consent. No experimental interventions were performed. An exempted Institutional Review Board (IRB) protocol was approved by Duke University (Pro00062871).

\section{Disclaimer}

Views expressed in the paper are solely of those authors and do not necessarily reflect those of Duke University, the United Nations, and New York University.

\section{Publisher's Note}

Springer Nature remains neutral with regard to jurisdictional claims in published maps and institutional affiliations.

\section{Author details}

${ }^{1}$ Duke University School of Nursing, Durham, NC, USA. ${ }^{2}$ Duke Global Health Institute, Duke University Medical Center, Durham, NC, USA. ${ }^{3}$ Department of Community and Family Medicine, Duke University Medical Center, Durham, NC, USA. ${ }^{4}$ Department of Sociology, Duke University, Durham, NC, USA. ${ }^{5}$ Duke Clinical Research Institute, Duke University Medical Center, Durham, NC, USA. ${ }^{6}$ United Nations Population Division, New York, NY, USA. ${ }^{7}$ New York University Rory Meyers College of Nursing, New York, NY, USA.

Received: 23 December 2016 Accepted: 9 May 2017

Published online: 15 May 2017

\section{References}

1. World Health Organization. World report on ageing and health. Geneva: WHO Press; 2015.

2. Ding D, Zhao Q, Guo Q, Meng H, Wang B, Luo J, et al. Prevalence of mild cognitive impairment in an urban community in China: a cross-sectional analysis of the shanghai aging study. Alzheimers Dement. 2015;11:300-9. e2

3. Ding D, Zhao Q, Guo Q, Liang X, Luo J, Yu L, et al. Progression and predictors of mild cognitive impairment in Chinese elderly: a prospective follow-up in the shanghai aging study. Alzheimers Dement. Diagnosis, Assess. Dis. Monit. Elsevier Inc. 2016;4:28-36.

4. Cotter VT. The burden of dementia. Am J Manag Care 2007:13(Suppl 8):S193-7.

5. Prince MJ, Wu F, Guo Y, Gutierrez Robledo LM, O'Donnell M, Sullivan R, et al. The burden of disease in older people and implications for health policy and practice. Lancet. 2014;385:549-62.

6. Zhao Y, Kuo T-C, Weir S, Kramer MS, Ash AS. Healthcare costs and utilization for Medicare beneficiaries with Alzheimer's. BMC Health Serv Res. 2008;8:108.

7. Phelan EA, Borson S, Grothaus L, Balch S, Larson EB. Association of Incident Dementia with Hospitalizations. JAMA J. Am. Med. Assoc. American Medical Association. 2012;307:165-72

8. Chan KW. Internal labor migration in China: trends, geography and policies. Popul. Distrib. Urban. Intern. Migr. Dev. An Int Perspect. 2012:81-102.

9. United Nations. World Urbanization Prospects: The 2014 Revision, Highlights (ST/ESA/SER.A/352). New York, United. 2014.
10. Meng X, Manning C, Li S. Effendi TN. The Great Migration, Rural-urban Migration in China and Indonesia. Cheltenham: Edward Elgar Pub; 2010

11. Xu H, Luo J, Wu B. Self-reported diabetes treatment among Chinese middle-aged and older adults with diabetes: comparison of urban residents, migrants in urban settings, and rural residents. Int J Nurs Sci. 2015;2:9-14.

12. Chen J. Chronic conditions and receipt of treatment among urbanized rural residents in China. Biomed Res Int. 2013;2013

13. Lu Y, Qin L. Healthy migrant and salmon bias hypotheses: a study of health and internal migration in China. Soc Sci Med Elsevier Ltd. 2014;102:41-8.

14. Tong $Y$, Piotrowski M. Migration and health selectivity in the context of internal migration in China, 1997-2009. Popul Res Policy Rev. 2012;31:497-543.

15. Chen J. Internal migration and health: re-examining the healthy migrant phenomenon in China. Soc Sci Med. 2011;72:1294-301.

16. Hu X, Cook S, Salazar MA. Internal migration and health in China. Lancet (London, England). 2008:372:1717-1719.

17. Cai F. Spatial patterns of migration under China's reform period. Asian Pacific Migr J. 1999;

18. Service Management Division of the National Population and Family Planning Commission for the Migrant Population. Report on China's migrant population development. Beijing: China Statistics Press; 2011.

19. Chan KW. China, internal migration. Encycl Glob Migr. 2006;2011:1-17.

20. Johnson I. China's great uprooting: moving 250 million into cities. New York, New York: New York Times; 2013 Jun 15.

21. Zeng Y, Gu D, Land KC. The association of childhood socioeconomic conditions with healthy longevity at the oldest-old ages in China. Demography. 2007;44:497-518.

22. Gelber RP, Petrovitch $H$, Masaki KH, Abbott RD, Ross GW, Launer LJ, et al. Lifestyle and the risk of dementia in Japanese-american men. J Am Geriatr Soc. 2012;60:118-23.

23. Lee SE, Diwan S, Yeo G. Causal attributions of dementia among Korean American immigrants. J Gerontol Soc Work. 2010;53:743-59.

24. Al Hazzouri AZ, Haan MN, Galea S, Aiello AE. Life-course exposure to early socioeconomic environment, education in relation to late-life cognitive function among older Mexicans and Mexican Americans. J Aging Health. 2011;23:1027-49.

25. Montes de Oca V, Garcia TR, Saenz R, Guillen J. The linkage of life course, migration, health, and aging: health in adults and elderly Mexican migrants. J. Aging Health. 2011;23:1116-40.

26. Sheffield KM, Peek MK. Neighborhood context and cognitive decline in older Mexican Americans: results from the Hispanic established populations for epidemiologic studies of the elderly. Am J Epidemiol. 2009/03/10. 2009; 169:1092-1101.

27. $\mathrm{Xu} \mathrm{H}$, Wu B. Association between Migration and Cognitive Status among Middle-Aged and Older Adults: A Systematic Review. Gerontologist. 2016; 56(Suppl 3):724

28. Raina SK, Raina S, Chander V, Grover A, Singh S, Bhardwaj A. Is dementia differentially distributed? A study on the prevalence of dementia in migrant, urban, rural, and tribal elderly population of Himalayan region in northern India. N Am J Med Sci. 2014:6:172-7.

29. Raina SK, Razdan S, Pandita KK. Prevalence of dementia in ethnic Dogra population of Jammu district, North India: a comparison survey. Neurol Asia. 2010;15:65-9.

30. Chan KW, Zhang L. The Hukou system and rural-urban migration in China: processes and changes. China Q. Cambridge University Press. 2009;160:818.

31. Deary IJ, Corley J, Gow AJ, Harris SE, Houlihan LM, Marioni RE, et al. Ageassociated cognitive decline. Br Med Bull. 2009;92:135-52.

32. Gow AJ, Avlund K, Mortensen EL. Occupational characteristics and cognitive aging in the Glostrup 1914 cohort. J Gerontol B Psychol. Sci. Soc. Sci. 2014;69:228-36.

33. Zhang Z, Gu D, Hayward MD. Childhood nutritional deprivation and cognitive impairment among older Chinese people. Soc Sci Med. 2010;71:941-9.

34. Wen M, Gu D. The effects of childhood, adult, and community socioeconomic conditions on health and mortality among older adults in China. Demography. 2011:48:153-81.

35. Unwin $N$, James $P$, McLarty D, Machybia H, Nkulila $P$, Tamin $B$, et al. Rural to urban migration and changes in cardiovascular risk factors in Tanzania: a prospective cohort study. BMC Public Health. 2010;10:272.

36. Oyebode O, Pape UJ, Laverty AA, Lee JT, Bhan N, Millett C. Rural, urban and migrant differences in non-communicable disease risk-factors in middle income countries: a cross-sectional study of WHO-SAGE data. PLOS One. 2015;10:e0122747 
37. Creavin ST, Gallacher J, Pickering J, Fehily A, Fish M, Ebrahim S, et al. High caloric intake, poor cognition and dementia: the Caerphilly prospective study. Eur J Epidemiol Springer Netherlands. 2012;27:197-203.

38. Lautenschlager NT, Cox KL, Flicker L, Foster JK, van Bockxmeer FM, Xiao J, et al. Effect of physical activity on cognitive function in older adults at risk for Alzheimer disease: a randomized trial. JAMA American Medical Association. 2008;300:1027-37.

39. Nooyens ACJ, van Gelder BM, Verschuren WMM. Smoking and cognitive decline among middle-aged men and women: the Doetinchem cohort study. Am J Public Health. 2008;98:2244-50.

40. Tuligenga RH, Dugravot A, Tabák AG, Elbaz A, Brunner EJ, Kivimäki M, et al. Midlife type 2 diabetes and poor glycaemic control as risk factors for cognitive decline in early old age: a post-hoc analysis of the Whitehall II cohort study. Lancet Diabetes Endocrinol. 2014;2:228-35.

41. Helmes E, Ostbye T, Steenhuis RE. Association between diabetes and cognition in older adults without dementia. J. Aging Res. Clin. Pract. 2013;2:264-70.

42. Lu Y, Hu P, Treiman DJ. Migration and depressive symptoms in migrantsending areas: findings from the survey of internal migration and health in China. Int J Public Health. 2012;57:691-8.

43. Dancygier RM, Laitin DD. Immigration into Europe: economic discrimination, violence, and public policy. Annu Rev Polit Sci. 2014;17:43-64.

44. Shankar A, Hamer M, Mcmunn A, Steptoe A. Social isolation and loneliness: relationships with cognitive function during 4 years of follow-up in the English Longitudinal Study of Ageing. Psychosom Med. 2013;75:161-70.

45. Kim KS, Lee YM, Lee HW, Jacobs DR, Lee DH. Associations between organochlorine pesticides and cognition in U.S. elders: National Health and nutrition Examination survey 1999-2002. Environ. Int. Elsevier Ltd. 2015;75:87-92.

46. Das I, Jagger P, Yeatts K. Biomass Cooking Fuels and Health Outcomes for Women in Malawi. Ecohealth. 2017;14:7-19.

47. Bruce N, Perez-Padilla R, Albalak R. Indoor air pollution in developing countries: a major environmental and public health challenge. Bull World Health Organ World Health Organization. 2000;78:1078-92.

48. Fullerton DG, Bruce N, Gordon SB. Indoor air pollution from biomass fuel smoke is a major health concern in the developing world. Trans. R. Soc. Trop. Med. Hyg. Oxford University Press; 2008;102:843-851.

49. Kioumourtzoglou M-A, Schwartz JD, Weisskopf MG, Melly SJ, Wang Y, Dominici F, et al. Long-term PM2.5 Exposure and Neurological Hospital Admissions in the Northeastern United States. Environ Health Perspect. 2016;124:23-9.

50. Clouston SAP, Brewster P, Kuh D, Richards M, Cooper R, Hardy R, et al. The dynamic relationship between physical function and cognition in longitudinal aging cohorts. Epidemiol Rev. 2013;35:33-50.

51. Finkel D, Ernsth-Bravell M, Pedersen NL. Temporal dynamics of motor functioning and cognitive aging. J Gerontol A Biol Sci Med Sci. 2016;71:109-16.

52. Brayne C. The elephant in the room - healthy brains in later life, epidemiology and public health. Nat Rev Neurosci. 2007;8:233-9.

53. Ferri CP, Prince M, Brayne C, Brodaty H, Fratiglioni L, Ganguli M, et al. Global prevalence of dementia: a Delphi consensus study. Lancet. 2005;366:2112-7.

54. Mathuranath PS, Cherian PJ, Mathew R, Kumar S, George A, Alexander A, et al. Dementia in Kerala, South India: prevalence and influence of age, education and gender. Int J Geriatr Psychiatry. 2010;25:290-7.

55. Zeng Y. Introduction to the Chinese longitudinal healthy longevity survey (CLHLS). Heal. Longev. China. Dordrecht: Springer Netherlands; 2008. p. 23-38.

56. Folstein M, Folstein S, McHugh P. "Mini-mental state": a practical method for grading the cognitive state of patients for the clinician. Res: J. Psychiatr; 1975

57. Zeng Y, Jr DP, Vlosky D, Gu D. Healthy longevity in China: demographic, socioeconomic, and psychological dimensions. 2008.

58. Yi Z, Vaupel JW. Functional capacity and self-evaluation of health and life of oldest old in China. J Soc Issues. 2002;58:733-48.

59. Herzog AR, Wallace RB. Measures of cognitive functioning in the AHEAD Study. J Gerontol B Psychol Sci Soc Sci. 1997;52 Spec No:37-48.

60. Zhang Z, Gu D, Hayward MD. Early life influences on cognitive impairment among oldest old Chinese. J Gerontol B Psychol. Sci. Soc. Sci. 2008;63:S25-33.

61. Singer JD, Willett JB. Applied longitudinal data analysis. Model. Chang. event Occur. 2003.

62. Winship C, Radbill L. Sampling weights and regression-analysis. Sociol Methods Res. 1994;23:230-57.

63. Han W-J, Shibusawa T. Trajectory of physical health, cognitive status, and psychological well-being among Chinese elderly. Arch Gerontol Geriatr Elsevier Ireland Ltd. 2015;60:168-77.
64. Zhang Z, Plassman B, Xu Q, Zahner G, Wu B, Gai M, et al. Lifespan influences on mid- to late-life cognitive function in a Chinese birth cohort. Neurology. 2009;73:186-94.

65. Riosmena F, Wong R, Palloni A. Migration selection, protection, and acculturation in health: a binational perspective on older adults. Demography. 2013;50:1039-64.

66. Dannefer D. Aging as intracohort differentiation: accentuation, the Matthew effect, and the life course. Sociol Forum. 1987;2:211-36.

67. Elder GHJ, Johnson M, Crosnoe R. The emergence and development of life course theory. 2003.

68. O'Rand AM. The precious and the precocious: understanding cumulative disadvantage and cumulative advantage over the life course. Gerontologist. 1996:36:230-8.

69. Ferraro KF, Shippee TP. Aging and cumulative inequality: how does inequality get under the skin? Gerontologist. 2009:49:333-43.

70. Qin B, Plassman BL, Edwards LJ, Popkin BM, Adair LS, Mendez MA. Fish intake is associated with slower cognitive decline in chinese older adults. J Nutr. 2014;144:1579-85.

\section{Submit your next manuscript to BioMed Central and we will help you at every step:}

- We accept pre-submission inquiries

- Our selector tool helps you to find the most relevant journal

- We provide round the clock customer support

- Convenient online submission

- Thorough peer review

- Inclusion in PubMed and all major indexing services

- Maximum visibility for your research

Submit your manuscript at www.biomedcentral.com/submit
Biomed Central 